\title{
Efficacy and Safety of Ketorolac for Pain Management After Congenital Heart Surgery: A Comparison to Paracetamol
}

\author{
Shahram Amini, ${ }^{1}$ Ehsan Mahdavi, ${ }^{1}$ Ghasem Soltani, ${ }^{1,}$ Nahid Zirak, ${ }^{1}$ Mohammad Abbasi Tashnizi, ${ }^{2}$ Vida \\ Vakili, ${ }^{3}$ and Farideh Golhasani ${ }^{1}$ \\ ${ }^{1}$ Cardiac Anesthesia Research Center, Department of Anesthesiology and Critical Care, Mashhad University of Medical Sciences, Mashhad, IR Iran \\ ${ }^{2}$ Department of Cardiac Surgery, Mashhad University of Medical Sciences, Mashhad, IR Iran \\ ${ }^{3}$ Department of Community Medicine, Mashhad University of Medical Sciences, Mashhad, IR Iran \\ "Corresponding author: Ghasem Soltani, Cardiac Anesthesia Research Center, Department of Anesthesiology and Critical Care, Mashhad University of Medical Sciences, \\ Mashhad, IR Iran. Tel: +98-9151162810, Fax: +98-5138525209, E-mail: soltanigh@mums.ac.ir
}

Received 2015 September 30; Accepted 2015 November 14.

\begin{abstract}
Background: Pain is an unpleasant complication commonly observed following congenital heart surgery, but is not often treated properly.

Objectives: The current study aimed to investigate the efficacy and safety of ketorolac to manage postoperative pain after pediatric heart surgery.

Methods: Eighty-one pediatric patients undergoing cardiac surgery received either ketorolac $0.5 \mathrm{mg} / \mathrm{kg}$ or paracetamol $15 \mathrm{mg} / \mathrm{kg}$ for postoperative pain control every six and eight hours on the first and second postoperative days, respectively. The critical-care pain observation tool (CPOT) and the face, legs, activity, cry, consolability (FLACC) scale were employed to investigate the pain severity. The patients were also investigated for additional analgesic requirements, and associated complications including acute kidney injury, gastrointestinal discomfort and bleeding in patients.

Results: Patients in the ketorolac group experienced less pain than the ones in the paracetamol group. More fentanyl was required for pain relief in the paracetamol than the ketorolac group. Use of ketorolac was not associated with more adverse effects in comparison to paracetamol.

Conclusions: Ketorolac is safe and effective to manage postoperative pain after congenital heart surgery. It is more effective than paracetamol for pain relief and requires less additional rescue analgesic.
\end{abstract}

Keywords: Postoperative Pain, Congenital Heart Surgery, Ketorolac, Paracetamol

\section{Background}

Pain is a common complication after congenital heart surgery with lots of challenges for the children, their parents and the health care providers.

Furthermore, it is often underdiagnosed and therefore not treated properly. Inappropriate management of postoperative pain is associated with deleterious effects including inadequate cough and clearance of pulmonary secretions and atelectasis especially in children, following heart surgery.

Opioids are often used to manage postoperative pain; nevertheless, they are associated with many adverse effects such as respiratory and cardiovascular depression. Therefore, use of non-opioid analgesics is popular among physicians caring for children undergoing cardiac surgery.

Paracetamol is a non-opioid analgesic commonly used to manage postoperative pain for different surgeries in children. It is used effectively and safely for pain relief after adult (1,2) and pediatric heart surgeries (3).

Non-steroidal anti-inflammatory drugs (NSAID) are used to control postoperative pain. However, their safety is questioned in children undergoing heart surgery. Ketorolac has been used safely to manage postoperative pain in different pediatric surgeries (3-8) including congenital heart surgery (9-11) with no adverse effects.

\section{Objectives}

The current study aimed to compare paracetamol and ketorolac in management of postoperative pain in congenital heart surgery. The primary outcome was comparison of pain score in the two groups. The secondary outcome included investigation of additional postoperative analgesic requirements and adverse effects including postoperative 
bleeding, acute kidney injury, gastrointestinal discomfort and bleeding following administration of the two drugs.

\section{Methods}

Eighty-one children over one year weighting more than $10 \mathrm{~kg}$ undergoing congenital heart surgery were recruited for the study. The ethics committee of Mashhad University of Medical Sciences approved the study and parents signed written informed consent forms before recruitment of their children. Using a computer based randomization, the patients were allocated to either intravenous paracetamol $(n=45)$ or ketorolac $(n=36)$ groups. The exclusion criteria were history of drug allergy, renal or hepatic insufficiency, unusual intraoperative or postoperative bleeding requiring blood products and peptic ulcer disease.

The patients in the paracetamol group received intravenous paracetamol $15 \mathrm{mg} / \mathrm{kg}$ every six and eight hours on days one and two, respectively.

Subjects in the ketorolac group received intravenous ketorolac $0.5 \mathrm{mg} / \mathrm{kg}$ every six and eight hours on days one and two, respectively.

The patients were evaluated for pain using critical pain objective tool (CPOT) (Figure 1) while intubated; and the face, legs, activity, cry, consolability (FLACC) scoring system (Table 1) when extubated at one hour intervals for 10 hours and every four hours up to 48 hours. They were given fentanyl $1 \mu \mathrm{g} / \mathrm{kg}$ for CPOT of $6-8$ and FLACC of $6-8$ and $0.5 \mu \mathrm{g}$ $/ \mathrm{kg}$ for CPOT of $3-5$ and FLACC of 3 - 5 .

The patients were also evaluated for development of adverse drug effects including postoperative bleeding, acute kidney injury using modified pediatric RIFLE (risk, injury, failure, loss of kidney function and end-stage kidney disease) criteria (Table 2), and gastrointestinal discomfort and bleeding.

The patients underwent a standard anesthesia with ketamine $1 \mathrm{mg} / \mathrm{kg}$, midazolam $0.1 \mathrm{mg} / \mathrm{kg}$, and fentanyl $1-5$ $\mu \mathrm{g} / \mathrm{kg}$ for induction and atracurium $0.6 \mathrm{mg} / \mathrm{kg}$ to facilitate endotracheal intubation. Anesthesia was maintained with isoflurane 1.2 - 2.5 minimum alveolar concentration (MAC) and additional fentanyl $5 \mu \mathrm{g} / \mathrm{kg}$ to maintain blood pressure and heart rates at $20 \%$ from baseline. Atracurium was given as $0.2-0.4 \mathrm{mg} / \mathrm{kg} /$ hour. The patients were transferred to the intensive care unit (ICU) while intubated where they were weaned from mechanical ventilation and extubated under a standard protocol. The children were under a standard monitoring including electrocardiography, invasive blood pressure, central venous pressure, end-tidal $\mathrm{CO}_{2}$, hear rates, respiratory rates and temperature.

A difference of $20 \%$ in pain intensity was considered clinically significant. A sample size of 68 was required to detect such a difference between the groups for a power of $90 \%$ at a significance level of $5 \%$. The sample size was increased to 80 in case of missing data. Data analyses were performed by SPSS software for Windows, version 16 (SPSS Inc, Chicago, IL, USA). Mean and standard deviation values for different variables were calculated. Independent Student T-test was used to compare continuous variables exhibiting normal distribution, and Chi-square or the Fisher exact tests for non-continuous variables. A P-value $<0.05$ was considered significant.

\section{Results}

Eighty-one patients were recruited for the study with the mean age of $50.40 \pm 23.80$ months. The patients were similar in both groups with respect to demographic characteristics (Table 3 ).

There were no significant differences between the two groups regarding duration of surgery, frequency of on pump surgery, cardiopulmonary pump and cross clamp time (Table 3).

Based on CPOT scale, pain score was significantly lower in the ketorolac $(3.25 \pm 2.48)$ than paracetamol group (5.22 $\pm 5.48)($ P-value $=0.049)($ Figure 2$)$.

The mean FLACC scores were $5.33 \pm 3.77$ and $8.02 \pm 7.44$ in the ketorolac and paracetamol groups, respectively ( $\mathrm{P}$ value $=0.05$ ) on the first postoperative day. On the second day, patients in the ketorolac group had FLACC score of 0.55 \pm 1.99 and the ones in the paracetamol group had FLACC score of $2.82 \pm 3.88$ (P-value $=0.01$ ) (Figure 3 ).

Patients in the ketorolac group required less fentanyl $(11.41 \pm 20.87 \mu \mathrm{g} / \mathrm{kg}$ ) than the ones in the paracetamol group $(16.45 \pm 15.90 \mu \mathrm{g} / \mathrm{kg})$ on the first postoperative day $(\mathrm{P}$-value $=0.33)$. No patients in the ketorolac group required additional fentanyl on the second postoperative day while those in the paracetamol group received fentanyl $2.44 \pm 4.95 \mu \mathrm{g} / \mathrm{kg}$ (P-value = 0.032).

Duration of mechanical ventilation was $2.4+3.2$ hours and $5.4+5.2$ hours in the ketorolac and paracetamol groups, respectively ( $\mathrm{P}$-value $=0.11$ )

The patients were similar with respect to development of acute kidney injury (AKI). No cases of gastrointestinal discomfort and bleeding were observed in the groups.

\section{Discussion}

The current study revealed that ketorolac was more effective than paracetamol to manage postoperative pain in children undergoing cardiac surgery. In addition, it can reduce postoperative additional analgesic requirement in comparison to paracetamol with no additional adverse effects. 


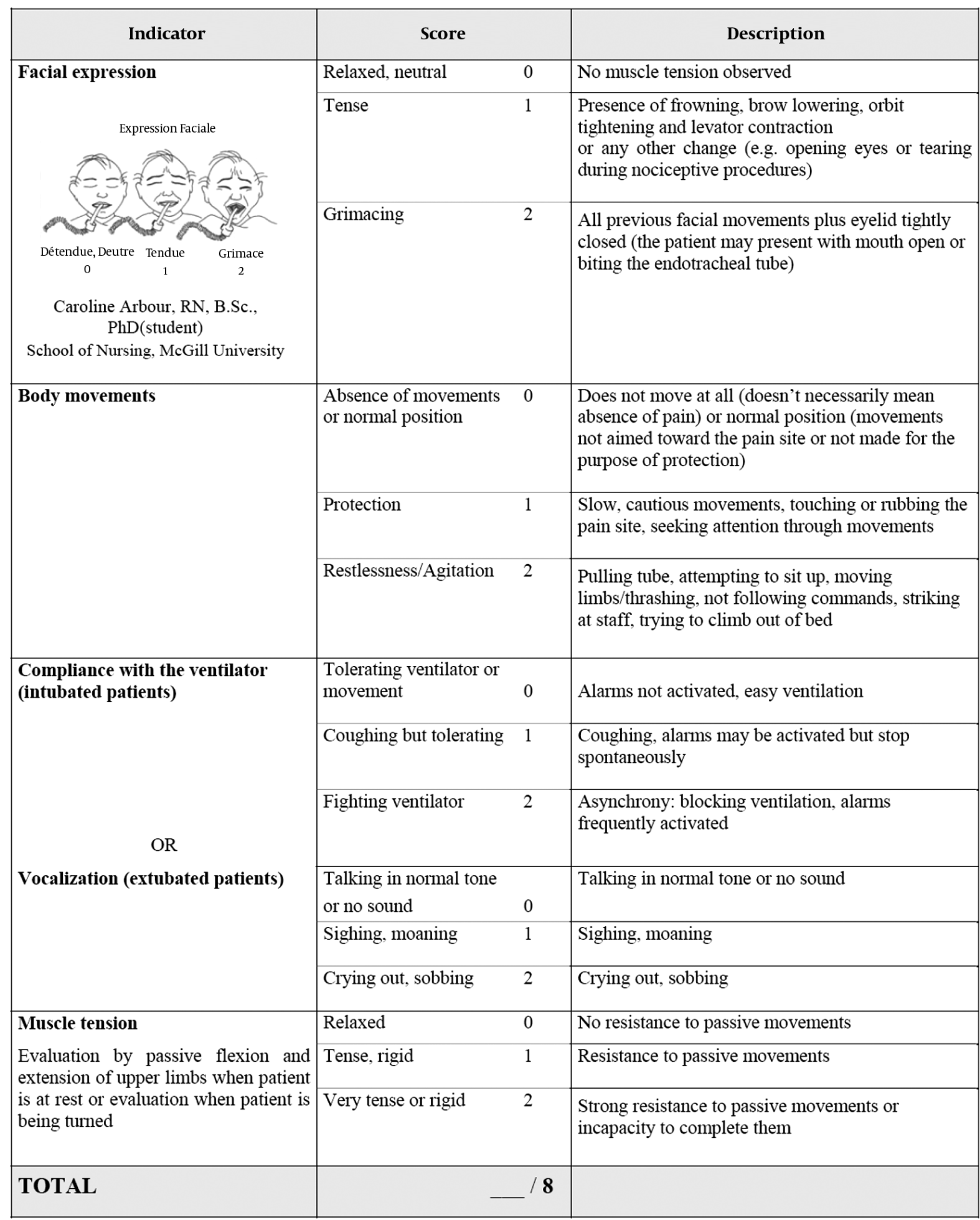

Figure 1. The СРОТ Scale 
Table 1. The FLACC Scale

\begin{tabular}{|c|c|c|c|}
\hline Criteria & Score - o & Score - 1 & Score-2 \\
\hline Face & No particular expression or smile & $\begin{array}{l}\text { Occasional grimace or frown, withdrawn, } \\
\text { disinterested }\end{array}$ & $\begin{array}{l}\text { Frequent to constant quivering chin, clenched } \\
\text { jaw }\end{array}$ \\
\hline Legs & Normal position or relaxed & Uneasy, restless, tense & Kicking, or legs drawn up \\
\hline Activity & Lying quietly, normal position, moving easily & Squirming, shifting back and forth, tense & Rigid or jerking \\
\hline Cry & No cry (awake or asleep) & Moans or whimpers; occasional complaint & $\begin{array}{l}\text { Crying steadily, screams or sobs, frequent } \\
\text { complaints }\end{array}$ \\
\hline Consolability & Content, relaxed & $\begin{array}{l}\text { Reassured by occasional touching, hugging or } \\
\text { being talked to distract }\end{array}$ & Difficult to console or comfort \\
\hline
\end{tabular}

Abbreviation: FLACC, the face, legs, activity, cry, consolability scale.

Table 2. Modified Pediatric RIFLE Criteria

\begin{tabular}{|c|c|c|}
\hline Category & $\begin{array}{c}\text { Estimated Creatinine } \\
\text { Clearance }\end{array}$ & \\
\hline \multicolumn{3}{|c|}{ Urine Output } \\
\hline Risk & Decrease by $25 \%$ & $\begin{array}{c}<0.5 \mathrm{~mL} / \mathrm{kg} / \text { hour for } 8 \\
\text { hours }\end{array}$ \\
\hline Injury & Decrease by $50 \%$ & $\begin{array}{c}<0.5 \mathrm{~mL} / \mathrm{kg} / \text { hour for } 16 \\
\text { hours }\end{array}$ \\
\hline Failure & $\begin{array}{c}\text { Decrease by } 75 \% \text { or }<35 \\
\mathrm{~mL} / \text { minute } / 1.73 \mathrm{~m}^{2}\end{array}$ & $\begin{array}{c}<0.3 \mathrm{~mL} / \mathrm{kg} / \text { hour for } 24 \\
\text { hours or anuric uremia for } \\
12 \text { hours }\end{array}$ \\
\hline Loss & \multicolumn{2}{|c|}{ Loss of renal function $>4$ weeks } \\
\hline End-Stage & \multicolumn{2}{|c|}{ End stage renal disease } \\
\hline
\end{tabular}

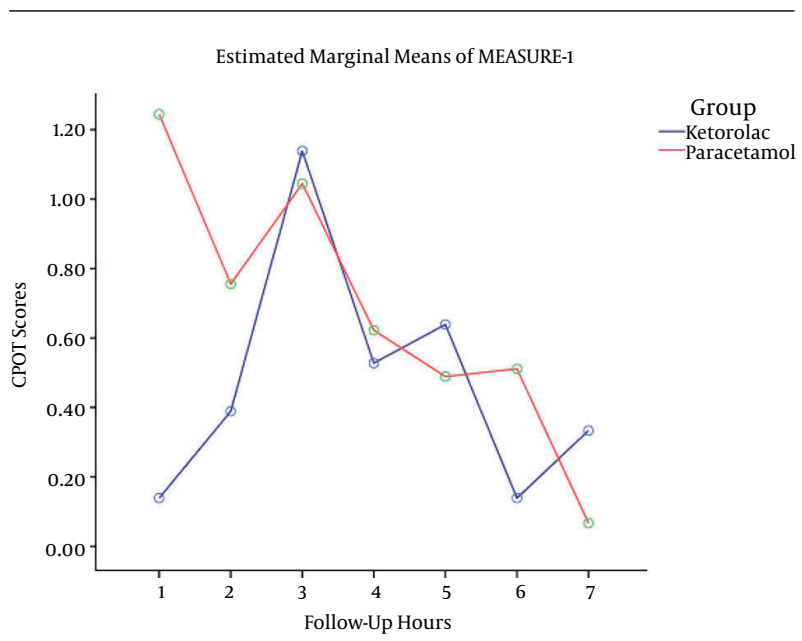

Figure 2. Pain Severity According to СРOT Scale in Patients Receiving Ketorolac and Paracetamol

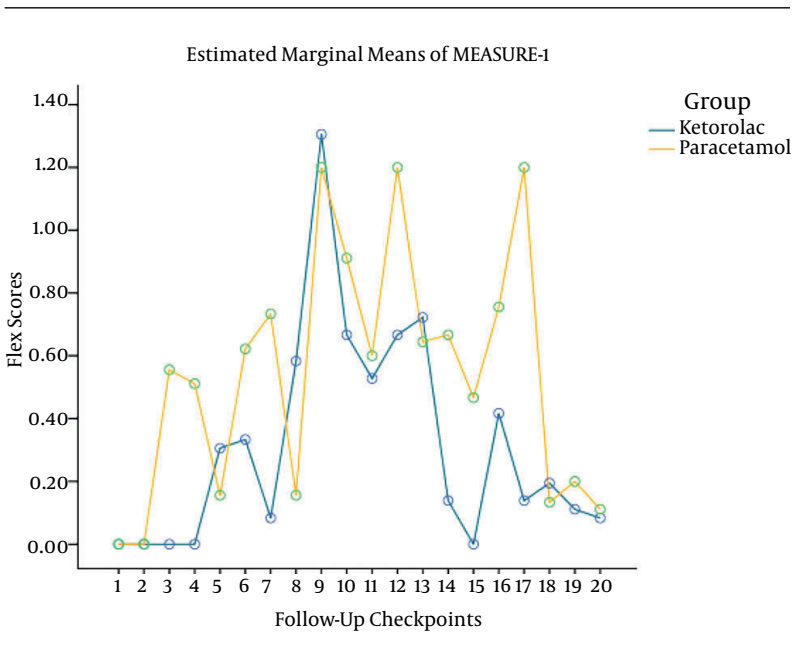

Figure 3. Pain Severity According to FLACC Scale in Patients Receiving Ketorolac and Paracetamol

Similar to the current study findings, some studies reported that paracetamol and ketorolac were both effective to manage postoperative pain following thyroidectomy (12) and parathyroidectomy (13). However, in the current series ketorolac was more effective in reducing pain; indicating that ketorolac was more effective in reducing moderate to severe pain experienced during cardiac surgery.

The obtained results showed that ketorolac reduced additional analgesic requirement postoperatively even better than paracetamol. It was in agreement with the report of Inoue et al. (10). Similar to the current study but in a different population, Burd et al. (14) and Chauhan et al. (15) also found that ketorolac was able to reduce the amount of additional postoperative opioid required after surgery in infants $(14,15)$.

In contrast to the current study, it was reported that patients with renal colic receiving paracetamol required less additional opioids in comparison to the ones in the ketorolac group (16). Different types of surgeries might explain this discrepancy. 
Table 3. Patients' Demographic and Surgical Data ${ }^{a}$

\begin{tabular}{|c|c|c|c|}
\hline Characteristic & Ketorolac & Paracetamol & PValue \\
\hline Age & $4.4 \pm 4.5$ & $3.2 \pm 2.8$ & 0.8 \\
\hline Gender & & & 0.1 \\
\hline Male & 42.9 & 59.1 & \\
\hline Female & 57.1 & 40.9 & \\
\hline Weight, Kg & $15.1 \pm 5.3$ & $16.4 \pm 7.8$ & 0.39 \\
\hline Height, Cm & $102.4 \pm 20.6$ & $101.06 \pm 22.8$ & 0.7 \\
\hline Off Pump, No. (\%) & $2(5.6)$ & 0 & 0.10 \\
\hline On Pump, No. (\%) & $34(94.4)$ & $44(100)$ & 0.11 \\
\hline Pump time, Minute ${ }^{b}$ & $42.88 \pm 24.3$ & $39.58 \pm 29.6$ & 0.53 \\
\hline
\end{tabular}

${ }^{a}$ Values are expressed as mean \pm SD unless otherwise indicated.

${ }^{\mathrm{b}}$ Cross clamp time.

Application of nonsteroidal anti-inflammatory drugs (NSAIDs) in the perioperative period can be associated with hemostasis disturbance, pulmonary, gastrointestinal and renal dysfunction $(11,13,17)$. However, several investigations demonstrated safety of ketorolac regarding renal dysfunction following pediatric heart surgery $(10,11)$.

It is reported that single use of ketorolac is effective and safe in infants less than two years $(14,18)$. Furthermore, ketorolac had no adverse effects on wound healing (19) and perioperative bleeding $(19,20)$ in infants undergoing cardiac surgery.

Use of ketorolac was not associated with increased risk of renal dysfunction in the current series. It was confirmed by other studies $(10,11)$. In agreement with the current study, Jalkut et al. suggested that ketorolac could be used in specific pediatric patients after cardiac surgery with minimal risk of bleeding or renal dysfunction with appropriate dosing and duration of use (9).

In contrast, it is reported that the concomitant use of aspirin with ketorolac is associated with increased renal morbidity in small infants' post-cardiac surgery (21). However, the current study did not evaluate the effect of this combination on renal dysfunction.

Bleeding is proposed as a potential adverse effect of NSAIDs. However, there are a number of studies indicating that using ketorolac to manage postoperative pain in children after cardiac surgery does not increase the risk of postoperative bleeding $(11,19,22,23)$. Similarly, in our patients no significant postoperative bleeding was noticed in the ketorolac in comparison to the paracetamol group.

The current study had a few limitations. Distribution of surgeries was not similar in the two groups that might affect the nature and intensity of pain. Furthermore, amount of intraoperative opioids was not investigated in the two groups that might affect their postoperative pain and analgesic requirements.
It was concluded that both ketorolac and paracetamol can reduce pain intensity effectively and safely after pediatric heart surgery with no preference. However, more additional analgesic was required in the paracetamol group in the first two postoperative days. Furthermore, ketorolac was not associated with increased risk of renal dysfunction, gastrointestinal discomfort and postoperative bleeding.

\section{Acknowledgments}

Authors would like to thank nursing staff at Imam Reza cardiac surgery ICU, especially Mr. Ali Bahush and Ms. Akram Kiani, for their contribution to the study.

\section{Footnotes}

Authors' Contribution: Shahram Amini, study design and manuscript preparation and writing; Ehsan Mahdavi, study design and manuscript preparation; Ghasem Soltani, study design and writing; Nahid Zirak, data collection; Mohammad Abbasi Tashnizi, data collection; Vida Vakili, data analysis; Farideh Golhasani, manuscript preparation

Financial Disclosure: The authors declared no financial disclosure regarding the current study.

Funding/Support: The study was supported financially by deputy research of Mashhad University of Medical Sciences, Mashhad, Iran.

\section{References}

1. Bruce EA, Howard RF, Franck LS. Chest drain removal pain and its management: a literature review. J Clin Nurs. 2006;15(2):145-54. doi: 10.1111/j.1365-2702.2006.01273.x. [PubMed: 16422731]. 
2. Foruzannia K, Moshtaghiun H, Mirhosseini H, Abdolahi.M H, Golzar A. Comparative effects of tramadol, indomethacin, and acetaminophen in controlling pain after coronary artery bypass surgery. Anaesthesiol Intens Care J. 2009;30(61):32-40.

3. Baley K, Michalov K, Kossick MA, McDowell M. Intravenous acetaminophen and intravenous ketorolac for management of pediatric surgical pain: a literature review. AANA J. 2014;82(1):53-64. [PubMed: 24654353].

4. Richardson MD, Palmeri NO, Williams SA, Torok MR, O'Neill BR, Handler $\mathrm{MH}$, et al. Routine perioperative ketorolac administration is not associated with hemorrhage in pediatric neurosurgery patients. J Neurosurg Pediatr. 2016;17(1):107-15. doi: 10.3171/2015.4.PEDS14411. [PubMed: 26451718].

5. Chan DK, Parikh SR. Perioperative ketorolac increases posttonsillectomy hemorrhage in adults but not children. Laryngoscope. 2014;124(8):1789-93. doi: 10.1002/lary.24555. [PubMed: 24338331].

6. Sukhtankar DD, Lee H, Rice KC, Ko MC. Differential effects of opioidrelated ligands and NSAIDs in nonhuman primate models of acute and inflammatory pain. Psychopharmacology (Berl). 2014;231(7):137787. doi: 10.1007/s00213-013-3341-0. [PubMed: 24217900].

7. Holdgate A, Asha S, Craig J, Thompson J. Comparison of a verbal numeric rating scale with the visual analogue scale for the measurement of acute pain. Emerg Med (Fremantle). 2003;15(5-6):441-6. [PubMed: 14992058].

8. Thagaard KS, Jensen HH, Raeder J. Analgesic and antiemetic effect of ketorolac vs. betamethasone or dexamethasone after ambulatory surgery. Acta Anaesthesiol Scand. 2007;51(3):271-7. doi: 10.1111/j.13996576.2006.01240.x. [PubMed: 17257175].

9. Jalkut MK. Ketorolac as an analgesic agent for infants and children after cardiac surgery: safety profile and appropriate patient selection. AACN Adv Crit Care. 2014;25(1):23-30. doi: 10.1097/NCI.0000000000000002. [PubMed: 24441450].

10. Inoue M, Caldarone CA, Frndova $\mathrm{H}$, Cox PN, Ito S, Taddio A, et al. Safety and efficacy of ketorolac in children after cardiac surgery. Intensive Care Med. 2009;35(9):1584-92. doi: 10.1007/s00134-009-1541-1. [PubMed: 19562323].

11. Dawkins TN, Barclay CA, Gardiner RL, Krawczeski CD. Safety of intravenous use of ketorolac in infants following cardiothoracic surgery. Cardiol Young. 2009;19(1):105-8. doi: 10.1017/S1047951109003527. [PubMed: 19134246].

12. Lee SY, Lee WH, Lee EH, Han KC, Ko YK. The effects of paracetamol, ketorolac, and paracetamol plus morphine on pain control after thyroidectomy. Korean J Pain. 2010;23(2):124-30. doi: 10.3344/kjp.2010.23.2.124. [PubMed: 20556214].

13. Anand A, Sprenker CJ, Karlnoski R, Norman J, Miladinovic B, Wilburn $\mathrm{B}$, et al. Intravenous acetaminophen vs. ketorolac for postoperative analgesia after ambulatory parathyroidectomy. Scandinavian J Pain. 2013;4(4):249-53. doi: 10.1016/j.sjpain.2013.06.001.

14. Burd RS, Tobias JD. Ketorolac for pain management after abdom inal surgical procedures in infants. South Med J. 2002;95(3):331-3. [PubMed: 11902701].

15. Chauhan RD, Idom CB, Noe HN. Safety of ketorolac in the pediatric population after ureteroneocystostomy. J Urol. 2001;166(5):1873-5. [PubMed: 11586252].

16. Shekari M. The effect of paracetamol, morphine intravenously and intravenous ketorolac control of renal colic pain in patients presenting to the emergency room [in Pesian]. Bandar abbas univ med sci. 2014.

17. Iorno V, Landi L, Di Pasquale R, Cicenia S, Moschini V. Comparison of intravenous ketorolac with or without paracetamol in postoperative pain control following ambulatory surgery. Curr Med Res Opin. 2013;29(12):1685-90. doi: 10.1185/03007995.2013.835256. [PubMed: 23998433].

18. Lynn AM, Bradford H, Kantor ED, Andrew M, Vicini P, Anderson GD. Ketorolac tromethamine: stereo-specific pharmacokinetics and single-dose use in postoperative infants aged 2-6 months. Paediatr Anaesth. 2011;21(3):325-34. doi: 10.1111/j.1460-9592.2010.03484.x. [PubMed: 21199130].

19. Gupta A, Daggett C, Drant S, Rivero N, Lewis A. Prospective randomized trial of ketorolac after congenital heart surgery. J Cardiothorac Vasc Anesth. 2004;18(4):454-7. [PubMed: 15365927].

20. Bosek V, Smith DB, Endicott J, Klotch D, Ridley M. Comparison of intravenous ketorolac and alfentanil as supplements to propofol anesthesia for diagnostic panendoscopy. J Clin Anesth. 1995;7(1):40-3. [PubMed: 7503851].

21. Moffett BS, Cabrera A. Ketorolac-associated renal morbidity: risk factors in cardiac surgical infants. Cardiol Young. 2013;23(5):752-4. doi: 10.1017/S1047951112001680. [PubMed: 23088994].

22. Moffett BS, Wann TI, Carberry KE, Mott AR. Safety of ketorolac in neonates and infants after cardiac surgery. Paediatr Anaesth. 2006;16(4):424-8. doi: 10.1111/j.1460-9592.2005.01806.x. [PubMed: 16618297].

23. Gupta A, Daggett C, Ludwick J, Wells W, Lewis A. Ketorolac after congenital heart surgery: does it increase the risk of significant bleeding complications?.PaediatrAnaesth. 2005;15(2):139-42. doi: 10.1111/j.14609592.2005.01409.x. [PubMed: 15675931]. 